\title{
Acculturation and integration: Language dynamics in the rural north-urban south mobility situation in Ghana
}

\author{
Gladys Nyarko Ansah \\ Senior Lecturer \\ Department of English \\ University of Ghana, Legon, Ghana \\ E-mail: gansah@ug.edu.gh; glasd514@yahoo.co.uk
}

Submitted: November 13, 2017/Accepted: March 20, 2018/Published: June 8, 2018

\begin{abstract}
This paper examines the role acculturation plays in the acquisition of Akan as L2 among young female migrants of northern Ghana origin (Kayayei), in their host communities in the south. While the literature is replete with studies on the migration of Kayayei to urban markets in the south, many of these studies are concerned with either sociological factors or economic ones or even health. Very little research has focused on the linguistic dimension of rural-urban migration in Ghana. Under the basic assumptions of Schumann's Acculturation Model, a socio-psychological model of L2 learning, this paper employs mixed methods (structured interviews, participant observation) to investigate Akan as L2 acquisition among Kayayei in three highly multilingual urban markets in Ghana. The analysis of the data revealed that whereas social dominance patterns do not seem to affect acculturation among Kayayei in Akan acquisition and use in the selected urban markets, other social and psychological factors, e.g. size of immigrant group, residence, and length of period of stay/hope of return to home origin which tend to result in limited/full integration, do. The findings of this paper resonate with Hammer's (2017) finding about the relationship between sociocultural integration of migrants and the extent of their use of L2, i.e., that L2 learners with higher levels of acculturation tend to have higher levels of proficiency in the $\mathrm{L} 2$.
\end{abstract}

Keywords: language and migration, Ghana, Akan acquisition, acculturation, Kayayei

\section{Introduction}

Ghana is a highly multi-ethnic/multilingual community with varying degrees of sociolinguistic vitality (Anderson \& Ansah, 2015; Ansah, 2014). According to Lewis et al (2017), there are over 80 languages in Ghana spoken by a population of about 27 million. Accra, the capital of Ghana has become the melting pot not only for all these ethnolinguistic groups in Ghana but also for other migrants from the West African sub-region and indeed, other parts 
of the world.

The last twenty years have seen the southward movement of mostly young females from the northern parts of Ghana into the southern cities of Accra, Kumasi, Takoradi, and others for longterm, short-term, or seasonal stays, to engage in various activities of economic value, popular among which is the carrying of load (for a fee) around markets in these cities (Anamzoya, 2001). This has resulted in the naming of this group of migrants as Kayayei (head porters), the plural form of 'Kayayoo', a compound word which is derived from two languages: Hausa and Ga. The first morpheme, 'kaya' comes from the Hausa word for 'luggage'. The second morpheme, 'yoo/ye' is the Ga word for 'female' (Coffie, 1992). Thus, a 'Kayayoo' (plural -'Kayayei') is a female who carries luggage for a fee or for commercial purposes.

This paper focuses on Kayayei from three urban markets in Accra, the most urbanised and capital city of Ghana. The markets are: Agbogbloshie Market, Madina Market and Dome Market. The Madina community and its market were established in the late 1950s when a group of migrants were given land to settle (Quarcoo et al 1967, Ntewusu, 2005). The Agbogbloshie Market/community is a fairly recent settlement emerging in the late 1990s (Awumbilla et al, 2013). Located close to the Central Business District of Accra, it has become the destination point of many migrants in the city of Accra. The Agbogbloshie community and market have been merged in a way that makes separating the business and residential settlements difficult. Finally, the Dome market is located within Dome-Kwabenya also in the Greater Accra Region. Unlike the Madina and Agbogbloshie settlements, the Dome town is not a typical migrant community. The town itself is inhabited by indigenous people and permanent migrant residents. However, the outlying settlements have been dominated by migrants who come to work in the market. Most of the residents in Dome are traders but a small number are civil servants.

These markets were selected because they are popular for both wholesale and retail distribution of major staple foods in Ghana 
which are brought in from different parts of Ghana and even beyond, e.g. Burkina Faso, Niger, Nigeria and Togo. Secondly, large migrant communities have sprung up around them, making them and their surrounding communities fertile sites for academic research, particularly, migration research. Not surprisingly, there have been many studies that have focused on these communities (Awumbilla et al, 2013; Ntewusu, 2005; Anamzoya, 2001). Nevertheless, these studies have not focused on the linguistic dimensions to migration. In other words, even though Kayayei have perceptively been studied by social scientists from different perspectives (Agarwal et al, 1997; Apt et al, 1992; Ardayfio-Schandorf \& Kwafo-Akoto, 1990), there is very little research on the linguistic dimensions to migration in Ghana. This paper is a modest contribution to address this imbalance.

Migration has profound sociolinguistic consequences because it alters the demographic balance of both the sending and receiving communities (Kerswill 1994, 2006). For example, while migrants tend to form an ethnolinguistic minority which has to relate sociolinguistically to a new 'host' community on the one hand, on the other hand, the host community, which becomes transformed by the arrival of migrants, also has to relate to the migrant community. The relationship between language and identities (e.g. ethnic identity, social class, gender) is well documented in ethnolinguistics and sociolinguistics (Ansah \& et al, 2017; Omoniyi \& White, 2006; Antaki \&Widdicombe, 1998).

It has been argued that in every case of migration, except where a homogeneous group of people moves to an isolated location, language or dialect contact ensues (Thomason \& Kaufman, 1988; Trudgill, 1986, as cited in Kerswill, 2006, p.19), and cultural and linguistic integration become a vehicle for social cohesion in language contact situations. Research has shown a strong relationship between migration, integration and language. In other words, language is a central component of interaction, assimilation and integration of immigrants into their host societies (Esser, 2006, p.7). For instance, language constitutes both the medium of everyday communication and a resource, particularly in the context 
Ansah, G. N./ Language dynamics in the rural north-urban south mobility situation of education and the labour market. Thus, there is a growing body of literature now which addresses different dimensions of the language and migration nexus.

Nevertheless, most of these studies focus on international migration (Capstick, 2011, p.8; Trajkovski \& Loosemore, 2006). In the African context, Büscher et al (2013) have investigated the relationship between language and identity in migratory situations and found a high rate of self-reported bi/multilingualism among Lingala migrants in Goma in the Democratic Republic of Congo (DRC) where L1 speakers of Lingala in Goma claimed to always complement their L1 with other languages that are considered necessary for survival in the city. The researchers' conclusion was that even though migrants maintain a minimum use of their home language in order to signal a national identity, in reality, they hardly use the L1 in the host community. This finding appears to be in direct contrast to what happens in other migratory contexts within Africa where migrants (attempt to) use a second language to either signal national identity or do cross-cultural business but where the L1 is mostly used in the host community outside work context (Vigouroux \& Mfwene, 2008).

Vigouroux (2013) has examined the relationship between language practice and labour in the context of migration (among Lingala immigrants in Cape Town, South Africa) and found that language plays a role in facilitating migrants' access to the job market and that lack of competence in a particular language may prevent migrants from making use of their occupational knowledge and experience acquired at home or indeed, from applying for positions within the labour market of the host community. Thus, the significance of language for the immigrants' integration into host societies or their successful engagement in economic activities in the host societies cannot be overemphasised.

The concepts of integration and assimilation explain the cohesion and stability of the component parts of the social structure. Integration is a two-way process. On the one hand, migrants have to accept the norms and cultures of the host societies (receiving communities). On the other hand, these host communities have 
Ansah, G. N./ Legon Journal of the Humanities 29.1 (2018) to respect migrants' dignity and their distinct identity, and more importantly, to take them into account when formulating policies. In the second language learning literature, the desire to learn a second language or otherwise has been closely linked to the learners' desire to integrate or assimilate into the culture of the second language community. Similarly, it has also been argued that the migrants' desire to integrate into host communities will be indexed by their willingness to learn the language of the host communities. The level to which the migrant attains the language of the host community (L2) has been linked to the migrant's ability to acculturate, adjust or adapt their social psychological selves to the socio-cultural realities of the speakers of the language of their host community (Hammer, 2017; Chizzo, 2002; Schumann, 1978).

\section{Acculturation}

The term 'acculturation' has generally been used by social anthropologists to describe the social changes and cultural contacts between different communities (Barjesteh \& Vaseghi, 2012). In other words, acculturation describes the dual process that affects the members of two or more cultural groups in contact as each adapts to the presence of the other (Berry 1997, cited in Barjesteh \& Vaseghi, 2012).

In the Second Language Acquisition (SLA) literature, the acculturation theory/model is an attempt to identify the causal variable(s) in Second Language Acquisition within the context of learning without instruction, (usually in immigration conditions), and in the environment where the second language can be mastered without study and instruction. Schumann (1978) defines acculturation in second language learning as the social and psychological integration of the learner with the (culture of the) Target Language (TL) group. The theory typically models second language acquisition by members of ethnic minority, e.g. immigrants, migrant workers or children of such groups, in natural contexts of majority setting.

This model holds that the degree to which L2 learners acculturate to the culture of target-language group generally depends on such social and psychological factors as social dominance patterns, 
Ansah, G. N./ Language dynamics in the rural north-urban south mobility situation enclosure, cultural similarity, attitude and motivation. One of the basic assumptions of this model is that L2 learners would acquire the Second Language (SL) only to the degree that they acculturate to the culture of the second language.

Of all the social and psychological factors identified by Schumann, social dominance is the most relevant to this paper. Schumann's Social Dominance theory is based on inter-group social hierarchy. According to Pratto et al (2006), human societies tend to organise as group-based social hierarchies in which at least one group dominates others. In other words, in inter-group relations, one or more groups are said to be dominant if they disproportionately enjoy greater positive social value and desirable material and symbolic resources, e.g. socio-political and economic power, including wealth, access to education, healthcare, quality food, good housing.

By default, social dominance tends to be reflected in language dominance -dominant cultures tend to have dominant languages in language-contact situations. This is because the languages of dominant groups tend to have more socio-economic and political capital/value. For instance, they tend to be recognised by governments as the languages of education, media and national communication or lingua francas. They also tend to receive sponsorship from government for development. Consequently, dominant languages tend to have high levels of vitality which further reinforce their dominance and facilitates their transformation into L2 for many people in the community (see Table 1 below for language dominance patterns in Ghana).

According to the acculturation model of second language learning, the only condition under which L2 learning thrives is when the culture of the second language learning group is equivalent (neither dominant nor subordinate) to that of the target language group. This is because both dominance and subordination (whether the second language learning group is dominant or subordinate to the target language group) will create a social distance between the two groups, causing resistance to learning the TL. With over eighty (80) ethnolinguistic groups spread across ten (10) in Ghana, social dominance is inevitable. 
While some ethnolinguistic groups enjoy national dominance, others enjoy local or regional dominance. Again, the dominance is determined by a variety of factors including linguistic vitality and socio-political status. For instance, with an indigenous population of about $49 \%$ of Ghana's total population, recognition by government as a medium of education in many lower primary schools in Ghana, widespread use in privately-owned media (TV and radio), Akan enjoys a high level of vitality and has become a dominant national group. Even though no other ethnolinguistic group in Ghana enjoys the kind of dominance Akan does at the national level, there are other dominant language groups nonetheless, especially at the local or regional levels. For example, Dagbani has a sizeable number of both native speakers and L2 speakers in northern Ghana and is also the indigenous and dominant language in the third largest city of Ghana, Tamale. Further, it is government-sponsored and used as a medium of instruction in education in the Northern Region, the largest administrative region in Ghana. However, not all the language groups from which the Kayayei migrate to Accra have social dominance. In the light of the claim in the acculturation model regarding dominance patterns and second language acquisition, this paper will examine the relationship between social dominance patterns and Akan as L2 learning among Kayayei in Accra.

Predictably, many criticisms have been levelled against the acculturation model of L2 learning (Larson-Freeman, 2007; Ellis, 1994; Farhady, 1981). For instance, the fact that the model focuses on social and psychological determinants only, leaving out other equally important factors in L2 learning, e.g. cognitive factors, has been documented (Barjesteh \& Vaseghi 2012). Again, Farhady (1981) bemoans the difficulty in operationally defining or experimentally testing the concept of acculturation.

In spite of these criticisms, this model has been applied/ adopted by many researchers to the investigation of L2 acquisition, especially, in migration situations. For instance, Chizzo (2002) studied the effects of acculturation on English (ESL) learning by a young Arab migrant in the United States of America. Again, Hammer (2017) has investigated the relationship between the level 
Ansah, G. N./ Language dynamics in the rural north-urban south mobility situation of integration among Polish migrants in the UK and their level of proficiency in English. Her study revealed that participants with higher levels of acculturation had higher levels of proficiency in English. Other social factors under acculturation that were found to affect the proficiency levels among participants included social network profile and length of residence.

In this paper, I re-examine some basic assumptions of Schumann's Acculturation Model, a socio-psychological model of L2 learning in the context of Akan learning and use by young female migrants (Kayayei) who live and work in three urban markets in Ghana. In the light of the assumptions of Schumann's acculturation model of second language learning and findings from previous studies, this paper interrogates the roles social dominance patterns play in the acculturation to and learning of Akan as L2 among Kayayei in the urban south of Ghana. Specifically, the paper examines whether or not migrants who are originally from sociolinguistic groups with high social dominance are more likely to acculturate to Akan, the dominant language of their host community than their counterparts from sociolinguistic groups with less vitality. Thus, this paper is guided by the following research questions:

(1a) What role does social dominance patterns play among the Kayayei in learning and using Akan?

(1b) Are migrants from sociolinguistic groups with high levels of vitality in northern Ghana more likely to acculturate to Akan than their counterparts from sociolinguistic groups with less vitality?

(2a) What is the level of acculturation among the Kayayei in their host communities?

(2b) How does the level of acculturation affect their acquisition and use of Akan, the dominant language in their host community? 


\section{Methods}

Mixed methods (e.g. structured interviews, participant observation) were used to collect data for analysis. As participant observers, the researchers ${ }^{1}$, visited the selected markets like regular customers going to do business in the markets. We first walked around the market to observe how other customers engaged the Kayayei. Each researcher then hired a Kayayoo and interacted with her. Subsequently, additional Kayayei were hired by each researcher under the pretext that he/she did not want to mix together certain items that had been bought in the same pan. Eventually, all the hired Kayayei were brought together at the carpark of the market in order to offload the groceries into a parked vehicle. Observations were made with regard to how the Kayayei interacted with one another. Notes were also taken on small note pads which also served as grocery list books.

With regard to the interviews, a total of one hundred and eighteen (118) young female migrants ${ }^{2}$ were interviewed over a ten-day period (December 2014) across the three markets. The Kayayei who were spotted in the markets carrying head pans (the major tool for carrying goods in the markets) and looking for job opportunity were engaged, their consent sought and subsequently interviewed. They were paid as though they had been hired for the duration of the interview. The data were collected with the aid of a well-structured interview guide. The interviews were structured to elicit information on respondents' basic demographic characteristics, period of stay in Accra, residence in their host communities, etc. There were also questions on respondents' choice of language in their interactions with both customers (at work) and friends (both at work and outside of work).

\footnotetext{
${ }^{1}$ The data on which this paper is based were collected as part of a larger, collaborative research that was funded by the Office of Research, Innovation and Development (ORID), University of Ghana, Legon. The team consisted of two sociologists, two linguists and four graduate students serving as research assistants

${ }^{2}$ The age distribution of the Kayayei was 10-43 years. However, the majority (72\%) were between the ages of 10 and 30 years.
} 
The research instrument was the same for all respondents. Faceto-face interviews and observation were adopted as the procedure for collecting primary data from our respondents. Whereas the interviews allowed for the elicitation of specific information, observation enabled the researchers to ascertain for ourselves the languages spoken amongst the Kayayei in their line of work. The interviews were conducted largely (but not solely) in the Twi dialect of Akan and Mole-Dagbani languages. This is because whereas the Twi dialect of Akan appears to be the dominant language of these markets (Ansah et al 2017), majority of the Kayayei were from the Mole-Dagbani ethnolinguistic groups e.g. Dagomba, Mamprusi and Nanumba. All data collected through interviews were either audiorecorded or hand-written. The data were analysed using SPSS to run simple descriptive tests (frequencies and cross tabulations).

\section{Findings \\ Social dominance and Akan acquisition}

In all, 94\% (111 out of 118) of the migrants self-reported as speaking one of eight (8) languages ${ }^{3}$ from northern Ghana, as their L1. Of this, 54.2\% spoke Dagbani/ Mampruli, 15.3\% spoke Sissala, 8.5\% spoke Tampulima, 7.6\% spoke Gonja, 3.4\% spoke Wale, 2.5\% spoke Frafra/Dagaati, 1.7\% spoke Hausa, and $0.8 \%$ spoke Kasena as their first language ${ }^{3}$. Figure1. below represents the first languages of the Kayayei we studied across the three markets.

3 While admitting that it would have been best to to use the convention/linguistic and politically correct terms for the se languages, we would rather not go into what that debate. Consequently, we have chosen to reproduce the exact information participants provided during the interview. 


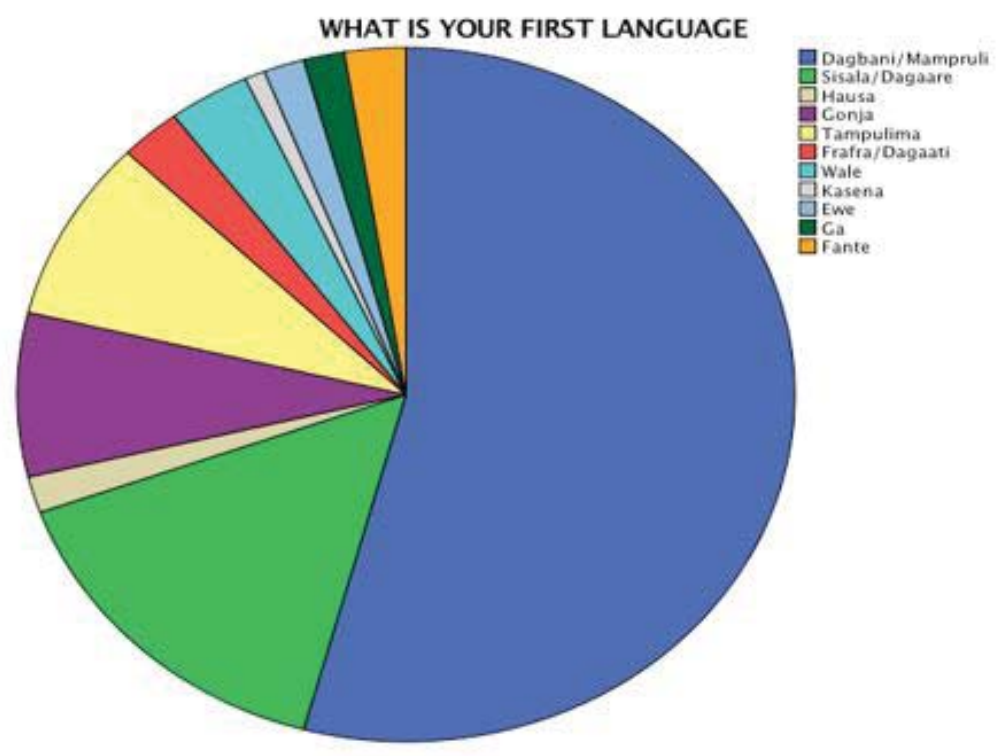

Figure 1: First language background of Kayayei

It is important to stress that these languages have different social dominance status compared to each other as seen in table 1 below. Whereas the dominance may be measured in terms of the sociolinguistic vitality of these languages (the number of native speakers) in some cases, (e.g. Frafra), it may also be measured in terms of their socio-political status, e.g., whether a language is government-sponsored, i.e. used in education, broadcasting, etc. (e.g. Kasena). Yet in other cases, social dominance is attributable to both sociolinguistic vitality and socio-political status, (e.g., Dagbani). Indeed, Dagbani, Frafra and Kasena are dominant languages in northern Ghana. They are spoken widely as L2 across northern Ghana. This notwithstanding, Akan, the main language in the markets in the south where the Kayayei migrate to, is a dominant language not only southern Ghana but indeed across the country and even beyond (Ansah, 2014). Table 1 below illustrates the social dominance patterns of Kayayei L1s in relation to Akan. 
Ansah, G. N./ Language dynamics in the rural north-urban south mobility situation

Table 1: Dominance patterns (Sociolinguistic vitality and sociopolitical status) of Kayayei L1s and Akan

\begin{tabular}{|l|}
\hline $\begin{array}{l}\text { Akan: about 12,000,000 natives (49.1\% Ghanaians); 44\% L2 } \\
\text { speakers; govern-ment- sponsored }\end{array}$ \\
\hline Dagbani: 1,160,000 natives; government-sponsored \\
Frafra: 720,000 natives; not sponsored \\
\hline Kasena: 250,000 natives; government-sponsored \\
\hline Gonja: 230,000 natives; government-sponsored \\
\hline Sissala: 180,000 natives; government-sponsored \\
\hline Wala: 140,000 natives; not sponsored \\
\hline Tampulima: 43,205 natives; not sponsored \\
\hline
\end{tabular}

Based on the assumptions of the social dominance argument of the acculturation model, one would expect that only Kayayei from dominant ethnolinguistic backgrounds from the north, i.e. Dagbani, Frafra and Kasena, representing 57.5\% of the 118 Kayayei, would have the social proximity to acculturate to Akan because of the equivalence in dominance. However, the data showed on the one hand that $77 \%$ of the 118 participants self-reported as speaking Akan as a second language while $89 \%$ of them self-reported as using Twi/Akan ${ }^{4}$ to transact business with clients. This finding suggests that whichever way one looked at it, there is evidence of acculturation across board - there is evidence of acculturation by Kayayei from non-dominant language groups. The remaining 11\% self-reported as using English and gestures to communicate with clients because they had been in the city for barely a month and did not have enough Akan to transact business in it.

4 Twi is the most widely spoken dialect of Akan both as L1 and L2. Very often, many lay people have treated Twi and Akan as synonymous. 
Further, in order to establish that the learning of Akan (if it occurs) takes place in their host communities, the Kayayei were asked to indicate whether they knew Akan before migrating to their current location. While 32\% (step-wise migrants) responded in the affirmative, $61 \%$ responded in the negative, and $6.8 \%$ made no comment. Participants who reported as speaking/using Akan were further asked to indicate where they learned Akan from. Again, while $8.2 \%$ indicated that they learned it in Kumasi, 91.8\% selfreported as learning it from Accra, where they presently reside. Both Table 2, which summarises the L2 spoken by the participants, and Figure 2, which is a cross tabulation of ethnolinguistic (L1) background and L2 spoken, corroborate the suggestion that among young female migrants (of northern origin) in urban markets in southern Ghana, social dominance patterns appear not to affect acculturation and L2 acquisition.

Table 2: L2 spoken by Kayayei

\begin{tabular}{|l|l|l|}
\hline Akan (Twi) & 91 & $77 \%$ \\
\hline English & 4 & $3.4 \%$ \\
\hline Tampulima & 2 & $1.7 \%$ \\
\hline Gonja & 1 & $0.8 \%$ \\
\hline No L2 & 16 & $13.6 \%$ \\
\hline No response & 4 & $3.4 \%$ \\
\hline
\end{tabular}

Thus, in answering questions $1(\mathrm{a} \& \mathrm{~b})$ - whether social dominance patterns play any role in learning and using Akan among the Kayayei and whether migrants from sociolinguistic groups with high level of vitality in northern Ghana are more likely to acculturate to Akan than their counterparts from sociolinguistic groups with less vitality, we may conclude thus: (a) Social dominance patterns appear not to influence acculturation (learning of Akan in the urban markets) among young female migrants of northern origin (Kayayei). (b) the sociolinguistic vitality of migrants' original ethnolinguistic group appears not to affect their 
tendency to acculturate to Akan.

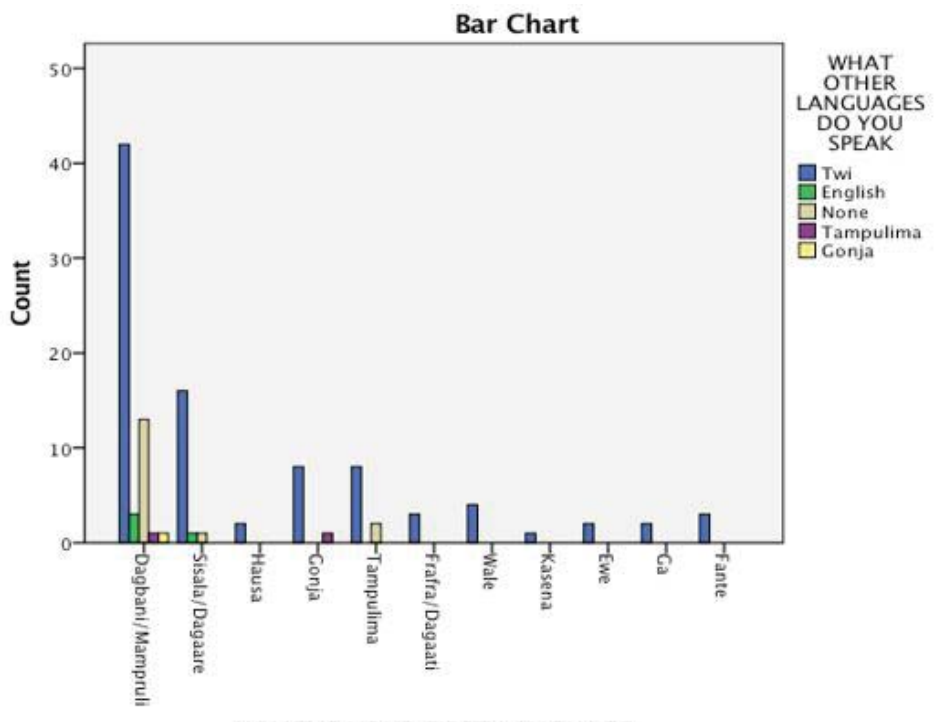

WHAT IS YOUR FIRST LANGUAGE

Figure 2: A cross tabulation of L1 background and L2 spoken

\section{The level of acculturation and Akan acquisition and use}

To answer questions $2(\mathrm{a} \& \mathrm{~b})$ : what the level of acculturation among the Kayayei in their host communities is, and how the level of acculturation affects their acquisition and use of Akan, A number of factors were examined. First, the patterns of residence in relation to migrants' workplace - whether they were diffused and mingled with other community members in their host communities were studied.

In all, 52 (44\%) of the 118 migrants self-reported as working at Agbogbloshie market, $31(26 \%)$ at Madina market and 31 (26\%) at the Dome market. Four (4) respondents did not indicate their place of work. Perhaps, this is because some of the migrants shuttle between market centres depending on need and job opportunities. Interestingly, $57(48 \%), 30(25 \%)$ and $31(26 \%)$ of the migrants 
reported as living in residences in and around Agbogbloshie, Madina and Dome markets respectively. This suggests that the Kayayei appear to form linguistic islands (typically, in groupings along ethnolinguistic lines) in their host communities (Ansah et al, 2017), i.e. they appear not to intermingle with the other members of their host communities, thereby limiting their contact with Akan to the domain of business. Thus, it may be concluded that there is a low level of acculturation among the Kayayei in their host communities, and that for many Kayayei, they only use Akan as a language for specific purposes.

With regard to the relationship between the level of acculturation and the acquisition and use of Akan among the Kayayei, the data analysis revealed that the level of acculturation affects L2 (Akan) acquisition among the Kayayei, i.e., Kayayei who have a high level of acculturation tended to acquire and use more Akan than those who have not. We identified the length of stay in the host community as one key factor that was closely connected to the level of acculturation. It appeared that the longer migrants have stayed in the host community, the more opportunity they have to acculturate, ie., interact with the host community and therefore learn their language. The data showed that Kayayei who had stayed in Accra longer ( 8 years and above) appeared to have become totally acculturated and used only Akan, the dominant language of the market in their line of business. However, migrants who had lived in the host community for a short time (1-12 months) used more languages (including gestures, what they called sign language) in their line of business in the markets. See Figure 3 below. 
Ansah, G. N./ Language dynamics in the rural north-urban south mobility situation

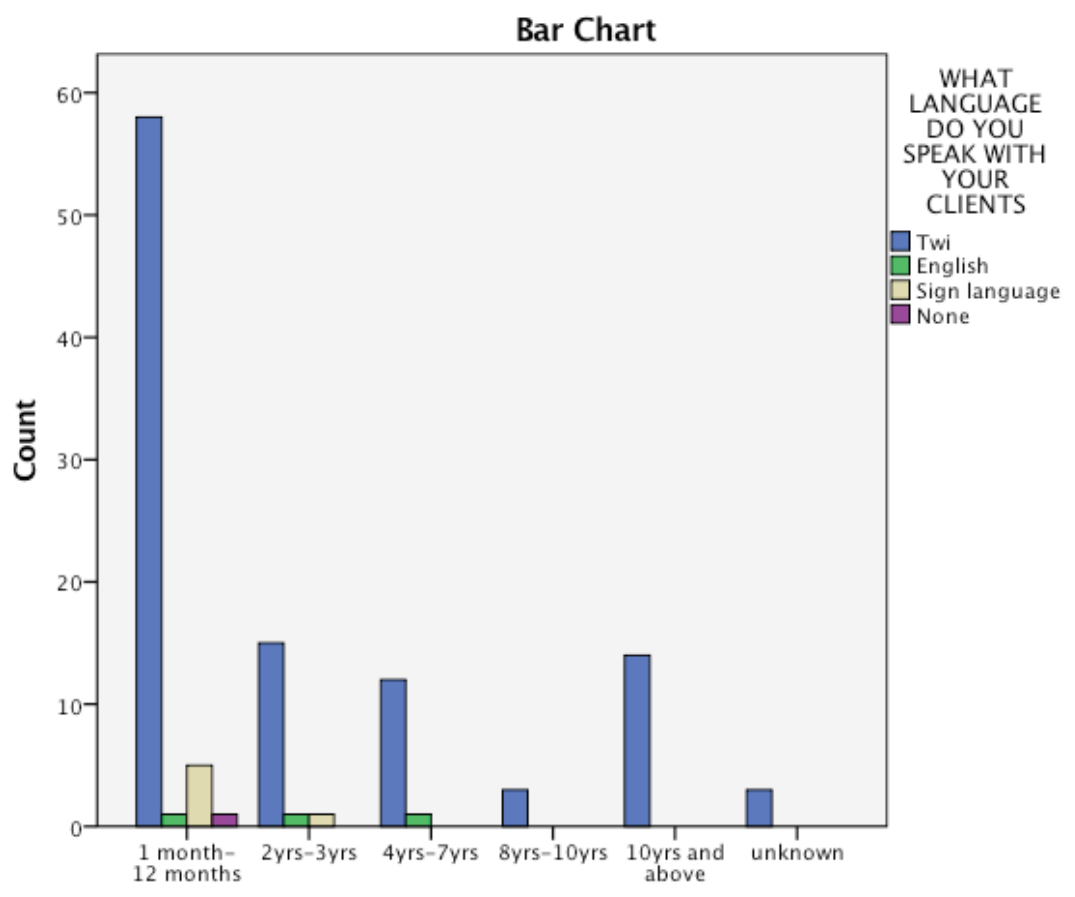

HOW LONG IN ACCRA?

\section{Figure 3: Length of stay and acculturation}

It is important to mention that while many of these migrants claimed to speak Akan, it was found out that neophyte migrants (who had lived in their host communities for 1-12 months) who were the least acculturated knew only formulaic Akan for the purposes of transacting business in the markets. They could not hold any meaningful conversation outside their line of business ( Ansah et al, 2017). Indeed, in certain instances, they would resort to code-switching or even the use of gestures in order to ease communication between them and their clients. However, migrants who had lived in their host communities longer were fluent and comfortable in using Akan both in their line of business and outside business. 


\section{Conclusion}

Ansah, G. N./ Legon Journal of the Humanities 29.1 (2018)

This paper has re-examined some basic assumptions of Schumann's acculturation model, a socio-psychological model of L2 learning in the context of Akan as L2 acquisition among young female migrants of northern origin (Kayayei) in three highly multilingual markets in urban Ghana. Specifically, the paper focused on the role of social dominance patterns as well as the level of acculturation in Akan as L2 acquisition among Kayayei in the selected urban markets. The analysis of the data revealed that social dominance patterns do not seem to affect acculturation among Kayayei in Akan acquisition and use in the selected urban markets.

However, other social and psychological factors, (namely, size of immigrant group, residence which tends to result in limited/ full integration, and length of period of stay/hope of return to home origin) appeared to affect Akan as L2 acquisition among the Kayayei. In other words, whereas the level of ethnolinguistic vitality or socio-political status of Kayayei's L1 background does not appear to influence their willingness to learn and use Akan in their host communities, where they settled in the host communities appeared to affect their integration levels and ultimately their motivation to learn and use Akan.

For instance, on the one hand, Kayayei who lived within their host communities together with people from other ethnolinguistic communities, as well as those who have lived in Accra for more than 12 months reported as using Akan more and appeared to have more competence in Akan. On the other hand, Kayayei who settled among other migrants from their own ethnolinguistic backgrounds tended to form linguistic islands in the host communities. This results in limited integration into their host communities (acculturation), and it ultimately affects their acquisition and use of Akan. The findings of this paper resonate with Hammer's (2017) finding about the relationship between sociocultural integration of migrants and the extent of their use of L2. 


\section{References}

Agarwal, S., Attah, M., Apt, N., Grieco, M., Kwakye, E. A., \& Turner, J.

(1997). Bearing the weight: The kayayoo, Ghana's working girl child. International Social Work, 40(3), 245-263.

Anamzoya, S. A. (2001). Mode of subsistence and adaptation among the kayayei in Accra. (MPhil thesis). University of Ghana, Legon.

Anderson, J. A., \& Ansah, G. N. (2015). A sociolinguistic mosaic of

West Africa. In D. Smakman \& P. Heinrich (Eds.), Globalising sociolinguistics: Challenging and expanding theory (pp. 54-65). London: Routledge.

Ansah, G. N., Anderson, J. A., Anamzoya, S. A., \& Ohemeng, F. (2017). 'Bra, $\mathrm{S} \varepsilon n, Y \varepsilon n k \jmath . .$. That is all I know in Akan’: How female migrants from rural north survive with minimum bilingualism in urban markets in Ghana. Ghana Journal of Linguistics, 6(1), 49-74.

Ansah, G. N. (2014). Re-examining the fluctuations in language in-education policies in post-independence Ghana. Multilingual Education, 4(1), 12.

Antaki, C., \& Widdicombe S. (1998). Identities in talk. Thousand Oaks, CA: Sage. Ardayfio-Schandorf, E., \& Kwafo-Akoto, K. (1990). Women in Ghana: An annotated bibliography. Accra: Woeli Publishing Services for UNFA.

Awumbila, M., Teye, J., Owusu G., \& Anamzoya S, A. (2013). Urbanization, rural-urban migration and urban poverty in Ghana: Regional Research Project Report. Brighton: Migration out of Poverty RPC, University of Sussex.

Barjesteh, H., \& Vaseghi, R. (2012). Acculturation model for L2 acquisition: Review and evaluation. Advances in Asian Social Science (AASS), 2(4), 579-584.

Büscher, K., D’hondt, S., \& Meeuwis, M. (2013). Recruiting a nonlocal language for performing local identity: Indexical appropriations of Lingala in the Congolese border town Goma. Language in Society, 42(5), 527-556.

Capstick. T. (2011). Language and migration: The social and economic benefits of learning English in Pakistan. In Coleman H. (Ed.), Dreams and realities: Developing countries and the English Language (pp.207228). London:British Council. Retrieved from https:// www.britishcouncil.jp/sites/default/files/eng-dreams-and-realities-en. pdf\#page $=207$

Chizzo, J. (2002). Acculturation and language acquisition: A look at Schumann's acculturation model. Retrieved from https://gse.gmu.edu/ assets/docs/lmtip/vol3/J.Chizzo.pdf,

Coffie E. A. (1992). Women's work in the informal sector: A case study of porters in the $31^{\text {st }}$ December market. (Student long essay, Department of Sociology). University of Ghana, Legon

Ellis, R. (1994). The study of second language acquisition. Oxford: Oxford University Press. 
Ansah, G. N./ Legon Journal of the Humanities 29.1 (2018)

Esser, H. (2006). Migration, language, and integration. AKI Research Review 4. Berlin: Programme on intercultural conflicts and societal integration (AKI). Social Science Research Center, www. wzb. eu/zkd/aki/files/ aki_research_review_4 (21.12. 2007).

Farhady, H. (1981). On the plausibility of second language acquisition models. Retrieved from http://www.eric.ed.gov/contentdelivery/servlet/ ERICServlet?

Hammer, K. (2017). Language through a prism: Patterns of L2 internalisation and use in acculturated bilinguals. Journal of Pragmatics, 117, 72-87.

Kerswill, P. (2006). Migration and language. Sociolinguistics/Soziolinguistik. An international handbook of the science of language and society, 3 , $1-27$.

Kerswill, P. (1994). Dialects converging: Rural speech in urban Norway. Oxford: Oxford University Press.

Larsen-Freeman, D. (2007). Reflecting on the cognitive-social debate in second language acquisition. The Modern Language Journal, 91, 773-787.

Lewis, M. Paul, Gary F. Simons, \& Charles D. Fennig (Eds.). (2016). Ethnologue: Languages of the World, Nineteenth edition. Dallas, Texas: SIL International. Online version: http://www.ethnologue. $\operatorname{com} / 19 /$.

Ntewusu. S. A. (2005): The Northern factor in Accra: A historical study of Madina Zongo as a sub-urban settlement 1957-2000. (PhD thesis, Institute of African Studies). University of Ghana, Legon

Omoniyi, T., \& White, G. (Eds.) (2006). The sociolinguistics of identity. London: Continuum.

Pratto, F., Sidanius, J., \& Levin, S. (2006). Social dominance theory and the dynamics of intergroup relations: Taking stock and looking forward. European Review of Social Psychology, 17(1), 271-320.

Quarcoo A.K, Addo. N.O, \& Peil. M (1967). Madina survey: A study of the structure and development of a contemporary sub-urban settlement. Institute of African Studies, University of Ghana, Legon.

Saville-Troike, D. (2006). Introducing second language acquisition. Cambridge, UK: Cambridge University Press.

Schumann, J. H. (1978). The pidginization process: A model for second language acquisition (pp. 1-113). Rowley, MA: Newbury House Publishers.

Thomason, S. G., \& Kaufman, T. (1988). Language contact, creolization, and genetic linguistics. Berkeley: University of California Press.

Trajkovski, S., \& Loosemore, M. (2006). Safety implications of low-English proficiency among migrant construction site operatives. International Journal of Project Management, 24(5), 446-452. 
Ansah, G. N./ Language dynamics in the rural north-urban south mobility situation

Trudgill, P. (1986). Dialects in contact. Oxford: Blackwell. Vigouroux, C. B. (2013). Informal economy and language practice in the context of migrations. In A. Duchêne, M. Moyer \& C. Roberts (Eds.), Language, migration and social inequalities: A critical sociolinguistic perspective on institutions and work, 2 (pp. 225-247). Bristol: Multilingual Matters.

Vigouroux, C., \& Mufwene, S. (2008). Colonization, globalization and language vitality in Africa: An introduction. In C. Vigouroux \& S. Mufwene (Eds.),Globalization and language vitality: Perspectives from Africa (pp.1-31). London:Continuum. 